\title{
Anterior Dental Microwear and Its Relationship to Diet and Feeding Behavior in Three African Primates (Pan troglodytes troglodytes, Gorilla gorilla gorilla and Papio hamadryas)
}

\author{
Alan S. RYan \\ The University of Michigan
}

\begin{abstract}
Anterior dental microwear is shown to be related to diet and to feeding habits in three groups of extant African primates including Pan troglodytes troglodytes, Gorilla gorilla gorilla and Papio hamadryas. Five distinct types of incisal microwear are found in these groups. These include: fine wear striae, polish, small pits, large pits and microflakes. It is demonstrated that each species exhibits a different set of microwear types. Chimpanzees exhibit extensive pitting, mesiodistally oriented fine wear striae and small areas of polish, features of microwear that are probably related to the husking of hard fruit skins and the occasional stripping of leaves. Gorillas show large areas of polish, small pits and labiolingually oriented wear striae, a combination of features that may be associated with the stripping of leaves and pith. Baboons show extensive edge damage involving clusters of large pits and microflakes; this set of microwear types may be related to the initial chewing of gravel-laden seeds, roots and rhizomes. Microwear found on the canine/premolar complex of all three groups corresponds to the puncture-crushing and to the slicing of food.
\end{abstract}

\section{INTRODUCTION}

The wide interest in the mechanisms of primate mastication has resulted in a growing literature concerned with the relationship between dental microwear and tooth use. In general, two kinds of approaches have been taken to study microscopic tooth wear. The first approach includes the attempts to provide information about occlusal relationships and the relative movements of opposing teeth during mastication (MILLS, 1955; BUTLER \& MILLS, 1959; KaY \& HiIEMAE, 1974a, b; KAY, 1973, 1975, 1977; Ryan, 1979a, b). In these studies, the orientation and direction of microscopic wear striations observed on molars has provided the basis for the reconstruction of jaw movements during chewing. The second approach includes the studies which focus on details of dental microwear that can be indicative of particular diets (P. WALKER, 1976; A. WALKER, 1979). Here, features of microwear are described in groups where the nature of the diet has been well documented. Using such data, investigators have then attempted to discover the diet of fossil primate species (A. WALKER, 1979; RYAN, 1980).

The present study centers on the relationship between anterior microscopic tooth wear and tooth use in three African primates including Pan troglodytes, Gorilla gorilla gorilla and Papio hamadryas. Anterior dental microwear found in these groups is described and related to aspects of diet and feeding behavior. These extant primates are particularly relevant for providing comparative data for the analysis of dental microwear in human fossil materials. While Pan and Gorilla represent man's closest living relatives, Papio occupies the savanna regions of Africa where australop thecines may have competed for similar resources (DEVORE \& WASHBURN, 1963). In addition, the ecology and behavior of these primates have been well 
documented in a series of excellent field studies (e.g., Kummer, 1968; Jones \& Sabater Pí, 1971; SCHAller, 1976; and others). Dental microwear observed on the anterior teeth of these primates is considered, keeping in mind the dietary and feeding behavior information provided by such field studies. The anterior dentition was chosen for this study because of its importance in the initial chewing of food. Dental microwear found on the canine/premolar complex is also considered in light of its importance in distinguishing nonhuman primates from humans.

\section{MATERIALS AND METHODS}

\section{Pan troglodytes troglodytes}

The ecology and behavior of wild chimpanzees have been described in detail (KORTLAND, 1962; Goodall, 1963, 1965, 1968; Jones \& Sabater Pí, 1971; Reynolds, 1965; Reynolds \& ReyNolds, 1965; SuZuki, 1969; Teleki, 1974, 1975; Wrangham, 1975; Nishida \& Uehara, 1980). Chimpanzecs are primarily frugivorous, although they eat leaves, bark and pith and supplement these staples with meat in the form of termites, ants and an occasional small monkey or bovid. Since the kinds of foods eaten by chimpanzees may vary considerably depending on ccological conditions, in order to relate microwear patterns on anterior teeth to aspects of feeding behavior and diet, care must be taken to determine the kinds of foods masticated by specific chimpanzee populations. The chimpanzees used in this study $(N=21)$ derive from Ebolowa, Cameroon, an area situated approximately 80 milcs north of Rio Muni, a part of the Republic of Equatorial Guinea (West Africa). These materials are currently housed in the Hamann-Todd primate collection, Cleveland Museum of Natural History. Detailed field studies of primates in Rio Muni were conducted over a two-year period (1966-1968) by Clyde Jones and Jorge Sabater Pí. It is reasonable to suggest that the data collected from Rio Muni dealing with food acquisition and feeding behavior may be comparable to that in Cameroon. In the study by Jones and SABATER Pí (1971), the ecology of the chimpanzee is compared to that of gorillas (see below). Using the data presented by these authors, dental microwear is related to the chewing and manipulation of certain plants.

\section{Gorilla gorilla gorilla}

The gorillas studied consisted of 15 wild shot adults which are part of the Hamann-Todd collection, Cleveland Museum of Natural History. As in the case of the chimpanzees, the gorillas were obtained from the Ebolowa area of Cameroon, West Africa.

As noted previously, the work on the western lowland gorilla in Rio Muni by JONES and SABATER Pí (1971) is particularly relevant to this study. Additional but limited ecological information concerning Gorilla gorilla gorilla can be found in MERFIELD and MILLER (1956), REYNOLds (1967), SABATER Pí (1966a, b) and SCHALLER (1976). It is generally recognized that gorillas eat large quantities of vegetation in the form of leaves and pith obtained from the forest floor. Microwear features on the anterior dentition of gorillas are considered with reference to the feeding behavior and dietary information provided by the above mentioned field studies.

\section{Papio hamadryas}

The last group of African primates considered in this study included 20 Papio hamadryas 
worn dentitions which are housed in the Hamann-Todd collection, Cleveland Museum of Natural History. These baboons are wild shot adults recovered from the semi-arid areas near Addis Ababa, Ethiopia.

In general, baboons live in a variety of habitats, and different species tend to occupy distinct ecological niches (CROOK \& Aldrich-BlaKe, 1968). Papio hamadryas, the baboon used here, occupies the semi-arid regions of eastern Sudan and the eastern lowlands of Ethiopia and Somalia (Kummer, 1968). Prior to 1960, the ecology and behavior of these animals were poorly known. Before that time, ZUCKERMAN (1932) and KuMMER (1957) reported aspects of social behavior based on observations made in the London and Zurich zoos, respectively. A detailed field study was carried out by KUMMER during 1960-1961 and published in 1968. This investigation focused on baboons living in the Danakil Plain of Ethiopia, not far from Addis Ababa. Many of the details concerning the diet and feeding behavior of these primates outlined in his monograph are used in this study. Papio subsists largely on gravel-laden seeds leaves, roots and rhizomes. Dental microwear in Papio provides insight into the kinds of wear features produced during the chewing of sandy foods obtained from the savanna.

\section{METHODS OF ANALYSES}

To facilitate microwear analysis, silicone rubber molds of tooth crowns were made from which epoxy resin casts were produced. The casting procedures used in this study are outlined in detail elesewhere (RYAN, 1979a, b, 1980).

For purposes of documentation and quantification two techniques were used. The first involved the use of $4^{\prime \prime} \times 5^{\prime \prime}$ micrographs to record fine aspects of m:crowear on selected portions of the tooth surface. The other technique required the mapping of total "occlusal" surfaces. ${ }^{1)}$ These occlusal surface composites were made for an upper right central incisor and the occluding lower at low magnification (35X) for each specimen. The labial enamel edge (Fig. 1) was often used as the horizontal axis during mapping. The use of the occlusal SEM (scanning electron microscope) composite offers certain advantages as compared to using single $4^{\prime \prime} \times 5^{\prime \prime}$ micrographs. A photographic record of the entire occlusal surface allows the determination of the extent of microwear variation across a given tooth. Selection of a specific area using single micrographs can only record features of wear in a small area, depending on the magnification used and the size of the tooth surface. Single micrographs used in this study were taken only to determine whether features of wear observed in the occlusal composites were similar to those seen on adjacent teeth within a given dental arcade. The types of microwear observed in the dental samples studied are described in Table 1. These types are discussed in greater detail in the Results section where distinct features of dental microwear are shown to be linked to certain dental activities and dietary conditions.

After occlusal composites were made and mounted on illustration boards, a transparent grid $(10 \mathrm{~mm} \times 10 \mathrm{~mm})$ divided into two components (one upper and one lower, Fig. 1) was placed upon the occlusal composite. This technique facilitated microwear counting and com-

1) Occlusal surface pertains to the contacting surface of opposing occlusal units (BOUCHER, 1963). A more specific term, namely incisal surface, is often used by the dental profession to describe the unworn surfaces of anterior teeth. The term incisal surface specifically refers to the "cutting edge" of anterior teeth. However, worn, flattened surfaces of incisors may not exhibit a cutting edge and therefore the more general term, i.e., occlusal surface, is used. 
Table 1. Types of dental microwear observed in Gorilla gorilla, Pan troglodytes troglodytes and Papio hamadryas.*

Depressions:

1. Small pits. These are small circular depressions with well defined borders that range in size from .03 to $.07 \mathrm{~mm}$.

2. Large pits. Large pits are morphologically similar to small pits but range in size from $.50 \mathrm{~mm}$ to $1.7 \mathrm{~mm}$.

Linear scratches:

1. Fine wear striae. Fine linear scratches parallel in alignment extend across enamel and dentine surfaces. Pits at the beginning of wear striae as well as narrowing tails are noted as being indicative of the direction of wear (see text).

Polish:

1. Polish. Polish involves surfaces that are worn (i.e., dentine cavitation of occlusal surface present) but exhibit no trace of any scoring (i.e., wear striae, pits or microflakes).

Edge damage:

1. Microflake. Microflaking results in smallwell defined pieces of enamel being removed from the occlusal surface. Flaked surfaces exhibiting edge rounding or fine wear striae are considered antemortem.

*These types of microwear are limited to the samples used in this study. Other types may be found in different dental materials (see RYAN, 1980). Therefore, the descriptions presented here represent a partial list.

putation of densities and distribution. Measurements of pits were taken along the horizontal axis of occlusal composites to determine maximum pit size diameter. Density figures, i.e., pits per unit area $\left(\mathrm{mm}^{2}\right)$, were computed in terms of their distribution: labial enamel, labial dentine, lingual dentine and lingual enamel (Fig. 1). The following formula was used to compute microwear type density:

$$
\text { No. of features } / \mathrm{mm}^{2}=\frac{\text { No. of features }}{\text { No. of boxes } \times(10 / \text { magnification })^{2}} .
$$

Fine wear striae were also counted to assess their relative densities on enamel and dentine surfaces. Orientation of wear striae was measured relative to a horizontal line passing through the long axis of the occlusal composite. Microflakes were counted to determine their frequency in each dental sample. In addition, microflakes were noted in terms of their distri-

\section{LINGUAL}

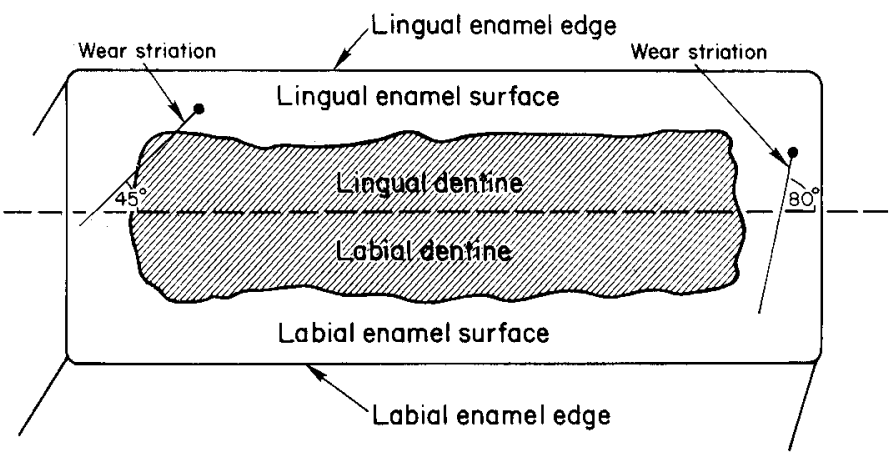

LABIAL

Fig. 1. Terms used to designate specific regions on the occlusal surfaces of worn incisors. Wear striation orientation is measured relative to a horizontal line passing through the long axis of the tooth surface. 
bution on an occlusal surface. Arrows in all occlusal composites are positioned labial to the tooth and point distally (Figs. 2A, B, 3, 4, 5, 6A-C).

\section{RESULTS AND DISCUSSION}

A description of dental microwear found on the incisors and on the canine/premolar complex of each primate dental sample studied is presented below. Densities of microwear types are summarized in Table 2. Microwear types found on incisors are related to the initial chewing of food, the kinds of foods eaten and feeding behavior. Dental microwear found on the canine/premolar complex is considered also to determine its role in mastication.

\section{Pan troglodytes troglodytes}

\section{InCisal Microwear (Figs. 2A, B)}

Dental microwear found on upper and lower incisors of $P$ an is characterized by three distinct and nonoverlapping types of wear. These include: (1) fine wear striae, (2) polish and (3) small pits. Each type is described below.

Fine wear striae are found to be equally distributed on enamel and dentine surfaces (Table 2) and extend over the labial enamel edge. Chimpanzees have wear striae that are oriented $37^{\circ}$ relative to a horizontal line passing through the long axis of the occlusal surface (see Fig. 1). In addition, in $10 \%$ of the individuals studied, mesiodistally oriented striae also are observed on the labial surface. The more mesiodistal inclination of wear striae as compared to that found in the other groups studied may indicate that foods containing abrasive material are drawn across teeth laterally. This suggested feeding behavior may not be limited to the chimpanzee. P. WALKER (1976) suggests that "tree-living colobines strip leaves from small terminal branches by pulling the branch laterally between incisors as an efficient way to obtain several leaves or small fruits with a minimum expenditure of energy."

Areas of polish also are observed but are not as pronounced as they are in gorillas (see be-

Table 2. Density, distribution and size of microwear types found on worn incisors.

\begin{tabular}{|c|c|c|c|}
\hline & 21 Pan & 15 Gorilla & 20 Papio \\
\hline $\begin{array}{c}\text { Density }\left(\text { per } \mathrm{mm}^{2}\right) \\
\text { labial enamel: } \\
\text { wear striae } \\
\text { pits }\end{array}$ & $\begin{array}{l}6.7 \\
6.5^{*}\end{array}$ & $\begin{array}{l}4.7 \\
2.0\end{array}$ & $\begin{array}{l}5.2 \\
2.0\end{array}$ \\
\hline $\begin{array}{l}\text { labial dentine: } \\
\text { wear striae } \\
\text { pits }\end{array}$ & $\begin{array}{l}4.7 \\
3.2\end{array}$ & $\begin{array}{l}3.0 \\
1.8\end{array}$ & $\begin{array}{l}7.7^{*} \\
1.5\end{array}$ \\
\hline $\begin{array}{l}\text { lingual dentine: } \\
\text { wear striae } \\
\text { pits }\end{array}$ & $\begin{array}{l}3.6 \\
2.3\end{array}$ & $\begin{array}{l}2.5 \\
1.9\end{array}$ & $\begin{array}{l}7.9^{*} \\
1.0\end{array}$ \\
\hline $\begin{array}{l}\text { lingual enamel: } \\
\text { wear striae } \\
\text { pits }\end{array}$ & $\begin{array}{l}6.1 \\
3.5\end{array}$ & $\begin{array}{l}1.9 \\
1.8\end{array}$ & $\begin{array}{l}7.2 \\
2.5\end{array}$ \\
\hline $\begin{array}{l}\text { Mean pit diameter } \\
\text { Wear striation orientation } \\
\text { Microflakes }(N)\end{array}$ & $\begin{array}{c}.06 \\
37^{\circ} \\
2\end{array}$ & $\begin{array}{c}.06 \\
60^{\circ} \\
1\end{array}$ & $\begin{array}{l}.11^{*} \\
45^{\circ} \\
18\end{array}$ \\
\hline
\end{tabular}

*A sign test indicates a significantly greater value than in the other two groups. 
low). This is probably due to the relative high frequency of pits observed on the labial enamel surface. Polish in this sample may result from the action of small particles of grit introduced into the diet or found in certain plants (plant opals) that are repeatedly drawn across the occlusal surfaces during stripping activities. An experimental study has shown that polish can be produced when initially unworn teeth are repeatedly drawn across a gritty surface (RYAN, 1979b). The chewing of foods containing small amounts of grit or plant opals may also be a possible cause of polish.

The pits seen on the occlusal surfaces of chimpanzees are relatively small $(.06 \mathrm{~mm})$. These pits are heavily concentrated on labial enamel surfaces $\left(6.5 \mathrm{pits} / \mathrm{mm}^{2}\right)$. Small pits also cluster together to form larger depressions $(1.1 \mathrm{~mm})$. Pitting in chimpanzees may be related to the application of vertical forces during the husking of fruit containing abrasive material.

Another type of microwear observed on chimpanzee incisors is proximal edge damage. This type of wear is found in $10 \%$ of the sample, particularly in older individuals. Microflaking of mesial and distal borders of teeth may occur when particles of sand, plant opals, etc. are trapped between teeth during the initial slicing and chewing of food.

\section{Diet and Feeding Behavior}

The feeding behavior of chimpanzees observed in the wild can provide insight into the possible causes for the set of microwear types seen on incisors. Approximately $65 \%$ of all chimpanzees observed in the tropical rain forests of West Africa are in arboreal situations (Jones \& Sabater Pí, 1971). Goodall (1965) also notes that chimpanzees in East Africa (Tanzania) are in trees approximately $50-70 \%$ of the daylight hours. The arboreal preference of chimpanzees not only reflects their climbing abilities but also the availability of focds. It is reported by JONES and SABATER Pí(1971) that much of the food eaten by Pan is obiained in the high canopy. Although these apes consume pith, shoots, leaves and buds, they prefer fruits

Fig. 2. Occlusal SEM composites, Pan troglodytes troglodytes (Arrows in all SEM occlusal composities are positioned labial to the tooth and point distally.) (CMNH, Cleveland Museum of Natural History catalog number, No. 1721). A. The left $I^{1}$ illustrated in this SEM composite exhibits three features of dental microwear. These are: fine wear striae, small pits and polish. Fine wear striae in Pan are oriented more mesiodistally than those in Gorilla. Wear striae are probably produced when gritty leaves are drawn across tooth surfaces. Small pits also are observed, especially on the labial enamel and dentine surfaces. In the central portion of the labial enamel surface, these pits cluster together to form a larger depression. Marked pitting may reflect the chimpanzees preference for fruits which have hard exocarps (skins). Between wear striae and pits, areas of polish are observed. B. The left $I_{1}$ from the same individual exhibits features of wear like that seen on the left $I^{1}$ indicating that foods chewed by chimpanzees score upper and lower occluding teeth in a similar fashion.

Fig. 3. Occlusal SEM composite, Gorilla gorilla gorilla (CMNH No. 1731). The left $\mathrm{I}_{1}$ illustrated in this SEM composite is heavily worn and exhibits fine wear striae that are parallel in alignment and oriented perpendicular to the labial enamel edge. Wear striae are probably produced when gritty leaves and pith are drawn across teeth in a forward direction. A postmortem crack, oval in shape, is found in the middle of the dentine. Patches of debris are present in the dentine and on the lingual enamel surface.

Fig. 4. Occlusal SEM composite, Gorilla gorilla gorilla (CMNH No. 3430). The right $\mathrm{I}_{2}$ of this individual exhibits the most common set of microwear types found in the gorillas studied. Polish is the principal type of wear. Such polish can result from the action of fine grit repeatedly drawn across tooth surfaces. Small pits also are illustrated on the labial enamel surface. Pitting, in contrast to wear striae, may be related to the crushing of food containing grit. Postmortem cracks are found in the dentine surface. 
Fig. 2.

A

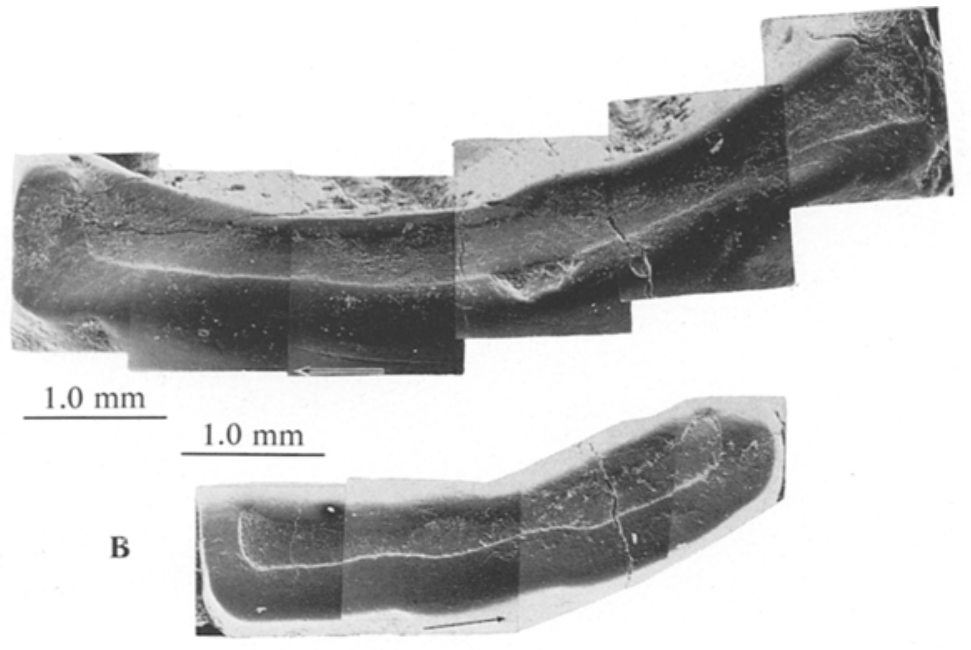

Fig. 3.

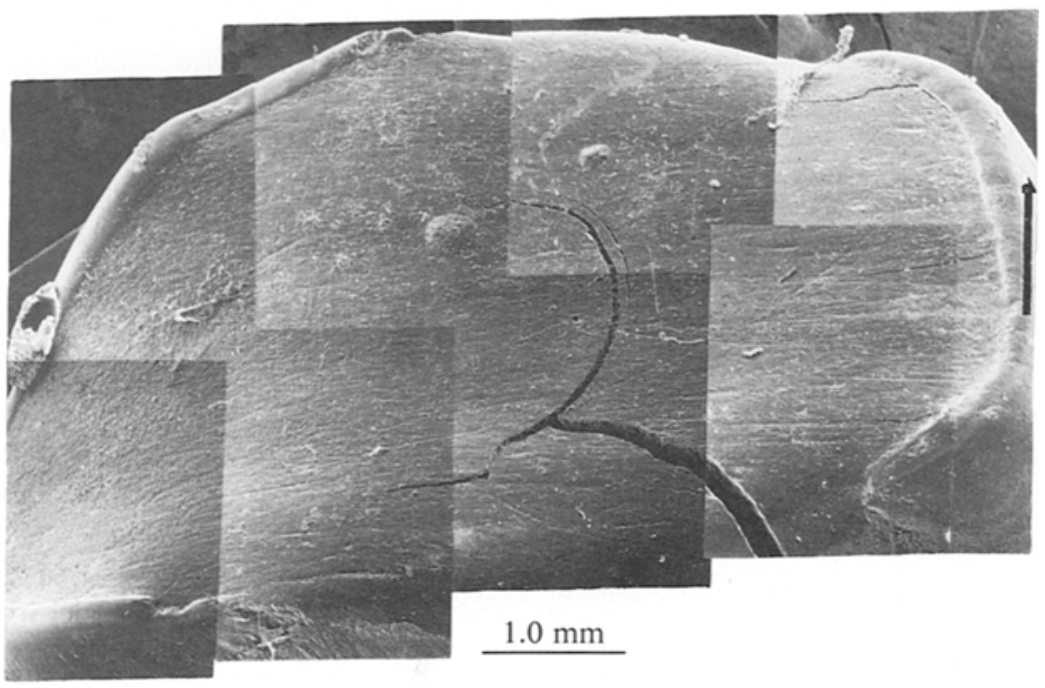

Fig. 4.

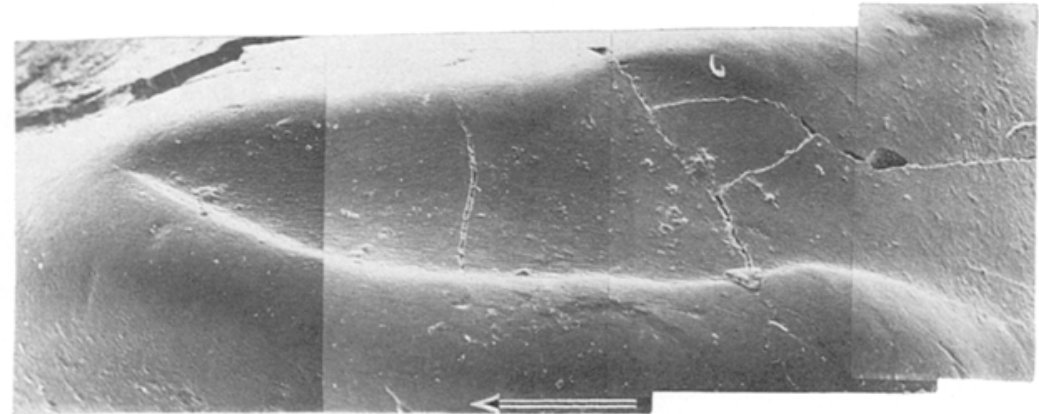

$1.0 \mathrm{~mm}$ 


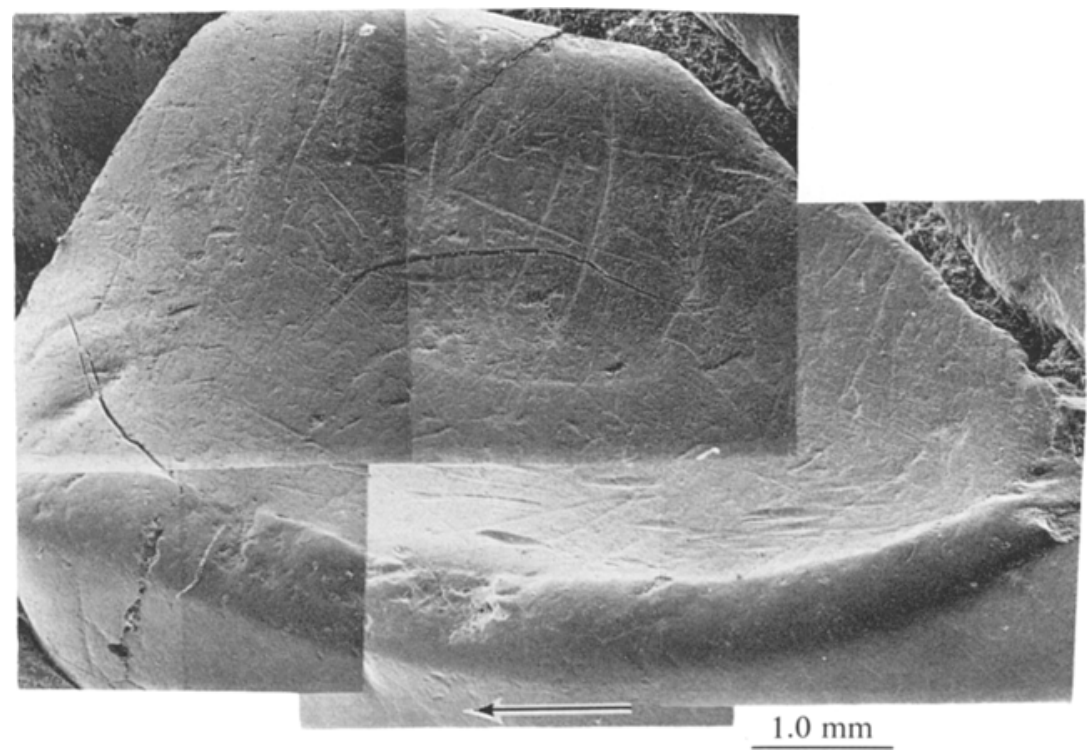

Fig. 5. Occlusal SEM composite, Papio hamadryas (CMNH No. 1219). The right $\mathrm{l}_{2}$ exhibits pronounced pitting along the labial enamel surface. These pits cluster together to form larger patches. In the dentine, wear striae crisscross each other in several directions. Large pits and dentine microflakes also are observed. The lingual enamel surface has been worn away. The extensive edge damage, large pits and dentine microflakes are probably associated with the initial chewing of gravel-laden seeds, roots and rhizomes. Wear striae, however, may reflect the action of gritty grasses drawn across tooth surfaces.

whenever they are available. The most important staple is the fruit of Brachystegia while the fruit of Aframomum, Musa and Saccharum are eaten occasionally (JoNES \& SABATER Pí, 1971). In addition to fruits, termite feeding is also observed in West Africa. Although predation of small mammals was not observed in Rio Muni, the acquisition of meat has been recorded at several sites in East Africa (Goodall, 1968; TeleKI, 1975). Studies in areas of savanna woodland also indicate that chimpanzees eat the fruit of Brachystegia but during the dry season the hard seeds of Julbernardia, Brachystegia, Isoberlinia and Pterocarpus are obtained from the open forest (SUzuKI, 1969).

The fine wear striae observed on chimpanzee incisors may be related to the action of drawing the pith of Aframomum and other plant foods across teeth. Chimpanzees remove pith from stems by clamping the stem with their anterior dentition, pulling the stem forward with their forelimbs while the head is jerked backward (Jones \& SABATER Pí, 1971). The inclination of wear striae $\left(37^{\circ}\right)$ indicates that a lateral movement of plant foods across teeth is involved. Mesiodistally oriented wear striae also result, perhaps, during the manufacture and utilization of termite probes. TELEKI (1974, Plate 2B) reports that "twigs and vines are stripped of leaves... and broken or bitten off to suitable lengths to make termite probes." Chimpanzees remove soldier termites from these probes by pulling the stick laterally across lips and teeth. In this latter activity, however, lips may be used to a greater degree than teeth.

The small pits and proximal edge damage observed on incisal surfaces may be due to the husking of fruits. JONES and SABATER Pí (1971) report that Brachystegia, the fruit eaten in large quantities by West African chimpanzees, has a thick, leathery skin (exocarp) ${ }^{2)}$ that 


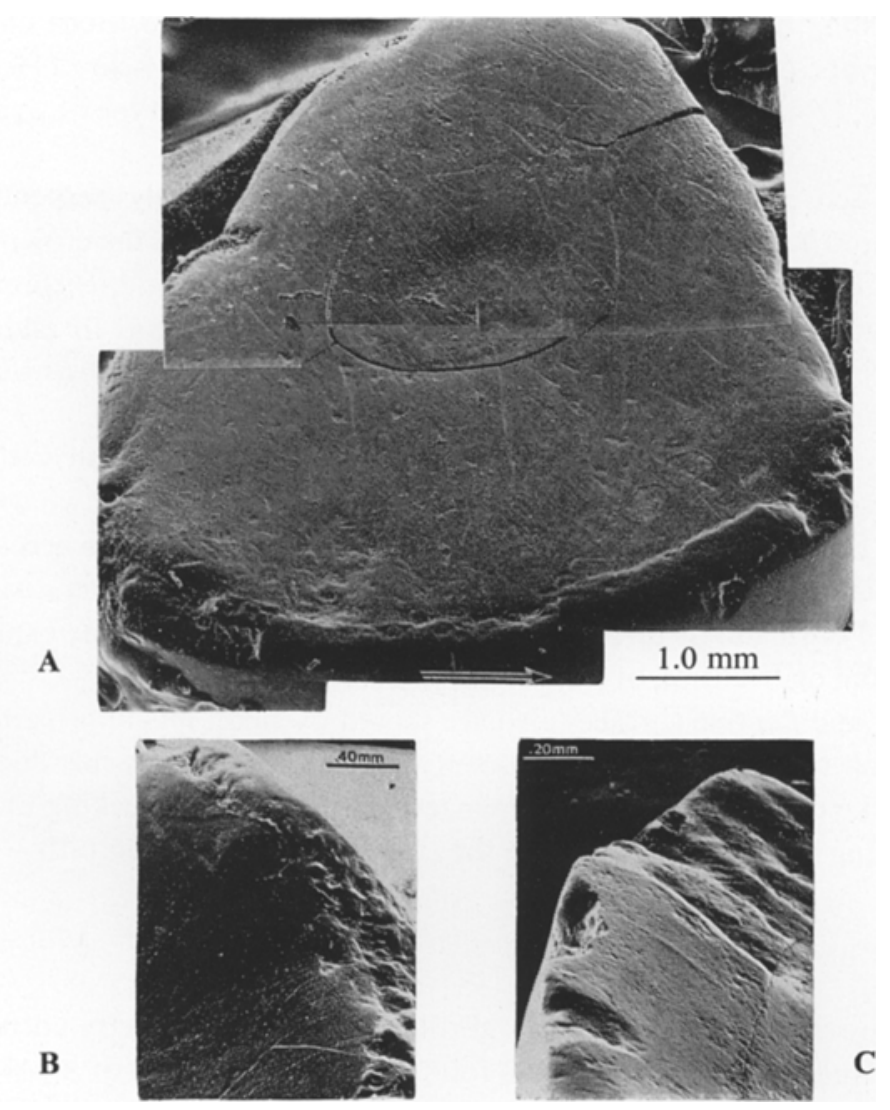

Fig. 6. An occlusal SEM composite and single SEM micrographs, Papio hamadryas (CMNH No. 1225). A. The left $I_{1}$ exhibits marked labial enamel edge damage and large pits in the dentine. Fine wear striae also score the dentine surface. B, C. Adjacent teeth of the same individual exhibit similar types of wear. On the left $I_{2}(B)$, large pits are observed on the labial enamel surface. On the right $\mathrm{I}_{2}(\mathrm{C})$, large microflakes are seen along the labjal enamel edge. Rounded edges and wear striae within the chipped areas indicate that microflaking occurred during the lifetime of this individual.

encases the inner, softer meat (mesocarp). ${ }^{2}$ It is possible that the exocarp of this fruit is highly abrasive and may produce the small pits and proximal microflaking seen on the occlusal surfaces. Due to the presence of polish on occlusal surfaces, it can be suggested further that certain fruits or meat chewed by the chimpanzee contain small amounts of plant opals or debris.

\section{Gorilla gorilla gorilla}

\section{INCISAL MiCROWEAR (Figs. 3 \& 4)}

The incisal microwear observed in the sample of western lowland gorillas also is evidently

2) Botanists use the terms exocarp and mesocarp to describe the outer most layer of the fruit wall and the inner spongy component of fruit, respectively (WEIER, StOcking \& BARBOUR, 1970). 
related to their feeding behavior and may reflect the nature of the foods chewed. Dental microwear on incisors of gorillas include three distinct types of wear: (1) labiolingually oriented wear striae, (2) large areas of polish and (3) small pits. Each type of wear is described below.

Fine wear striae score enamel and dentine surfaces approximately perpendicular to the labial enamel edge $\left(60^{\circ}\right)$ and extend over the edge toward the base of the crown. The orientation of wear striae in gorillas is significantly different from that found in chimpanzees $(p<$ .001 ) indicating that gorillas strip foods in a more forward direction. In addition, there is a great deal of variation between individuals in the appearance and distribution of wear striae possibly because of the extent of polish.

Twenty-five percent of all the occlusal composites made exhibit polish without evidence for any wear striae or pits. As previously noted, polish may result from two wear producing activities. The first involves the action of sandy material repeatedly drawn across the occlusal surface. Another possible cause of polish is the chewing of food containing small amounts of abrasive materials. Polish and its direct relationship to fine wear striae may explain the variation in the degree and distribution of wear striae in different individuals.

Both the enamel and dentine surfaces also are scored by small pits approximately $.06 \mathrm{~mm}$ in size. Although this type of wear is not frequenty observed $(15 \%)$ possibly due to the effects of polish, pitting like that observed in chimpanzees may reflect the husking of fruit without the horizontal pulling component related to the stripping of leaves and pith.

\section{Diet and Feeding Behavior}

The set of microwear types observed on gorilla incisors may directly correspond to the nature of their diet and to the ways they chew food. For example, fruits of Aframomum, which are found on small stalks at the base of the plant close to the ground, are first removed and then, using their anterior teeth, gorillas peel off and discard the exocarp (JONES \& SABATER Pí, 1971; SCHALLER, 1976). After this peeling process, the mesocarp is sliced off and chewed. The pith of Aframomum, on the other hand, is extracted from stems in a different manner. Stems are held horizontally between teeth with both hands, bitten into and then pulled away by a backward jerk of the head and forward pull of the forelimbs. "This combined motion (exposes) the pith, which (can be eaten) directly from the stem or pulled out with one hand to consume" (Schaller, 1976).

No evidence was obtained at Rio Muni that western lowland gorillas eat the fruit of $M u s a$ (JoNes \& Sabater Pí, 1971), Schaller (1976) also reports that mountain gorillas rarely eat the fruit. Rather, the pith of the stems is preferred. "Characteristically the whole banana tree is broken 2 to $4 \mathrm{ft}$ above ground. The stem is then ripped apart with hands and teeth and the pith extracted"' (ScHALLER, 1976).

Leaves of Sarophrynium and Trachyphryium are included in the diet of western lowland gorillas. "The parts of these plants eaten (are) the basal portion of the unrolled new leaves... (found) near the ground or within reach of the ground" (JONES \& SABATER Pí, 1971). Although the specific feeding behavior related to the initial chewing of these plants is not described by JONES and SABATER Pí (1971), it is reasonable to suggest that leaves are stripped off branches in a fashion similar to that used to extract pith.

A number of other food items eaten by the western lowland gorilla is described by JONES and SABater Pí (1971) while Schaller (1976) provides additional data on the kinds of 
plants eaten by other gorilla populations. Based on these studies, two feeding habits are generally observed. The first involves the tearing and shredding of stems, pith and leaves, while the second includes the husking of hard exocarps and the chewing of the softer mesocarps. Eacin feeding behavior directly corresponds to the dental microwear found on incisors. The labiolingually oriented wear striae and polish reflect the stripping of pith and leaves. On the other hand, the small pits probably correspond to the husking of hard exocarps and/or the chewing of mesocarps. Polish may also indicate that some food eaten by the gorilla contains low concentrations of grit. Although it is not possible at this time to determine precisely which food item produces a particular wear feature, it can be suggested that the combination of fine wear striae, large areas of polish and small pitting is indicative of a diet primarily consisting of leaves and pith and, to a lesser extent, fruit.

\section{Papio hamadryas}

\section{INCISAL Microwear (Figs. 5 \& 6A-C)}

In general, microwear on incisors of Papio hamadryas is more pronounced than that seen in the pongid samples studied. Although similar types of wear are observed including wear striae, polish and pits, the most noticeable types of wear consist of labial enamel edge damage and dentine microflaking. In addition, a plane of wear involving the initial removal of the central and lingual enamel surfaces is characteristic of all worn incisors. This wear process results in a well defined strip of labial enamel and a dentine surface that is considerably flattened. The lingual enamel surface in $40 \%$ of this sample is completely worn away.

Wear striae are found in high frequencies on dentine surfaces (Table 2). On the average, wear striation orientation is $45^{\circ}$. However, the inclination of wear striae varies considerably on individual teeth as clusters of striae form criss-crossing patterns. These clusters of wear striae are usually surrounded by areas of polish.

Isolated pits occur on enamel and dentine surfaces. Measurement of maximum pit size indicates that it is significantly larger than in apes $(.11 \mathrm{~mm})$. This suggests that focd eaten by Papio either contains larger particles of sand or debris or that larger vertical forces are applied to occluding teeth during initial chewing. Pits are often grouped together, especially on the labial enamel edge, forming a strip of extensive edge damage. The pitting observed on the labial enamel surface is usually associated with microflaking. Within these chipped surfaces, pits are observed. Small pits and microflakes are not restricted to the labial enamel surface but also are found along proximal borders. In addition, large isolated pits $(1.17 \mathrm{~mm})$ are observed in the dentine surfaces, although these depressions are not frequent in appearance $(8 \%)$.

Another type of wear involves large dentine microflaking. Fine wear striae and small pits are found on these chipped surfaces indicating that microflaking occurred during the individual's lifetime. Such dentine microflaking probably reflects isolated crushing activities when large particles of sand in seeds, roots or rhizomes are initially chewed.

\section{Diet AND FeEDing Behavior}

In the semi-arid regions of the eastern lowlands of Ethiopia, eastern Sudan and Somalia, the desert baboon, Papio hamadryas, eats foods obtained from the open savanna (KUMMER, 1968). Although wet and dry seasons greatly influence the foods available to baboons, aca- 
cias are reported to provide the main staples in both seasons (KUMMER, 1968). For example, during the dry season, the beans and dry leaves of acacia comprise $84 \%$ of the diet; while sisal leaves, the leaves of Dobra glabra, roots dug from the ground and green leaves of deciduous trees other than acacias provide the additional food resources (KUMMER, 1968). In the rainy season, the focus shifts to grass seeds $(44 \%)$ and acacia flowers $(43 \%)$ while fresh acacia roots, fruits of Dobra glabra and other food collected from the ground are eaten occasionally. Many of these foods, especially acacia flowers and shoots and the fruit of Dobra glabra are consumed in trees (KUMmER, 1968).

KUMMER (1971) reports that hamadryas baboons obtain the beans of acacias by picking them up from the ground and placing them into their mouths in rapid succession. The leaf bases of wild sisal, roots and rhizomes are freed from the ground by digging around them and pulling these plant materials upward using hands or teeth (Altmann \& Altmann, 1970). Although it has been reported that $P$. cynocephalus, while using similar methods to extract roots and rhizomes from the ground, often wipe or rub the dirt off plants before consumption (DeVore \& WASHBURN, 1963), it is probable that small amounts of sand adhere to the plant surfaces and are introduced into the diet. Sand particles as well as the reported tough nature of these food items (KUMMER, 1971) may produce the extensive edge damage and microflaking seen on incisors. Since pitting is rather limited to the labial enamel surfaces, it seems likely that the edges of occlusal surfaces initially serve to crush hard gravel-laden seeds, rhizomes and roots. Continued crushing of these foods may result in pits and dentine microflaking observed in the central dentine and proximal borders of the occlusal surfaces.

The grass leaves that are eaten by Papio hamadryas are prepared for initial chewing in a different fashion. Hamadryas is reported to "strip grass ears by pulling them through their closed jaws with one hand" (KUMMER, 1971). This feeding habit probably results in the wear striae found on occlusal surfaces. However, variation in wear striation orientation indicates that the forward pull of grasses occurs in several directions.

\section{Dental Microwear on the Pan, Gorilla and Papio Canine/Premolar Complex (Figs. 7A-D \& 8A-D)}

Tooth form, occlusal relationships and dental function involving the canine/premolar complex are well known features which distinguish certain nonhuman primates from hominids. In chimpanzees and gorillas, the maxillary canines are large, robust teeth projecting well beyond the occlusal plane, especially in males. Canine tooth sexual dimorphism is marked in the Pongidae. Male canines are large and reflect larger male body size and the "anatomy of bluffing and fighting" (WASHBURN \& ClOCHON, 1974). Although it has been demonstrated that canines tend to wear flat to the level of incisors, especially in females (ST. HoYME \& KORITZER, 1971), in general, both male and female modern pongids have maxillary canines with broad, thick mesial borders and narrow elongate distal edges which are sharpened by the honing buccal surface located on the sectorial or sharpening $P_{3}$ (SwINDLER, 1976). Sharpened canines are not only formidable weapons (particularly for males), they also serve to cut and puncture food.

Despite divergent dietary and feeding activities, microwear on the canine/premolar complex of chimpanzees and gorillas is similar. The honing buccal surface of the lower premolar possesses a large cutting edge. Wear striae extending down from the cutting edge also are observed. As indicated by individual wear striation morphology on the shearing edge of upper canines, sharpening and slicing of food are accomplished during a specific jaw movement, 

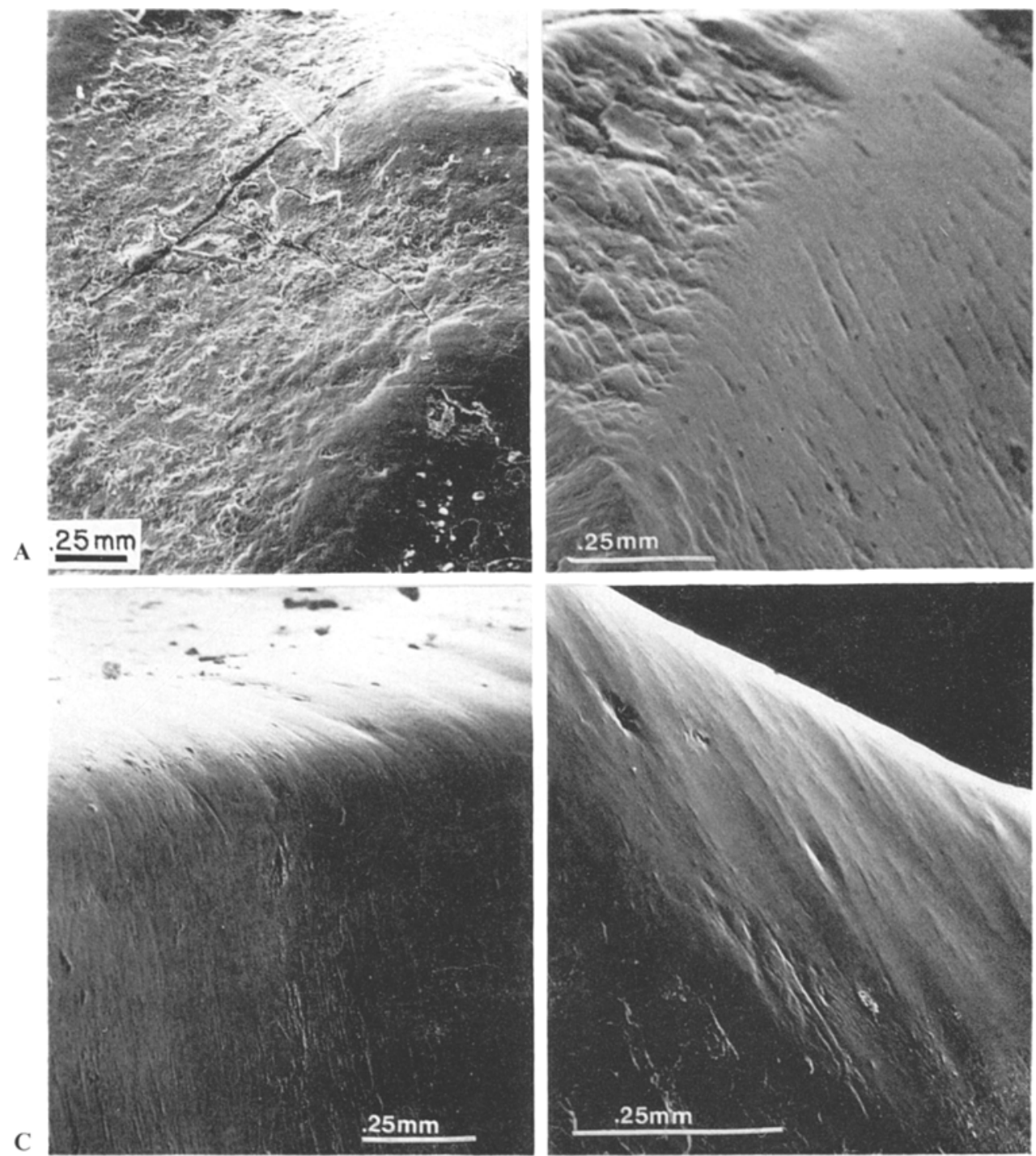

Fig. 7. Single SEM micrographs of dental microwear found on the canine/premolar complex of Gorilla and Pan. A. This SEM micrograph illustrates marked pitting on the protoconid of a left $P_{3}$ (Gorilla, CMNH No. 1728). Pitting and blunting of the cusp tip may be associated with puncturecrushing jaw movements during chewing. $B$. The honing buccal surface of a gorilla right $P_{3}(C M N H$ No. 18404)illustrated in this micrograph exhibits a shearing edge scored by fine wear striae and polish. C. The maxillary canine of Gorilla (CMNH No. $18404 ; L C$ ) usually shows wear striations that exhibit a morphology indicating that cutting of food and sharpening of canines occur during Phase I movements of the jaw (see text). D. The honing buccal surface of mandibular premolars of chimpanzees $\left(\mathrm{RP}_{3} ; \mathrm{CMNH}\right.$ No. 1058) as in gorillas is characterized by a shearing edge scored by fine wear striae and polish (see Fig. 7B).

Phase I of mastication (Crompton \& Hilemae, 1970). During Phase I, the mandible moves upward, forward and medially into centric occlusion. Wear striations originating near the shearing edge begin with broad pits and have extending grooves that become narrower, 

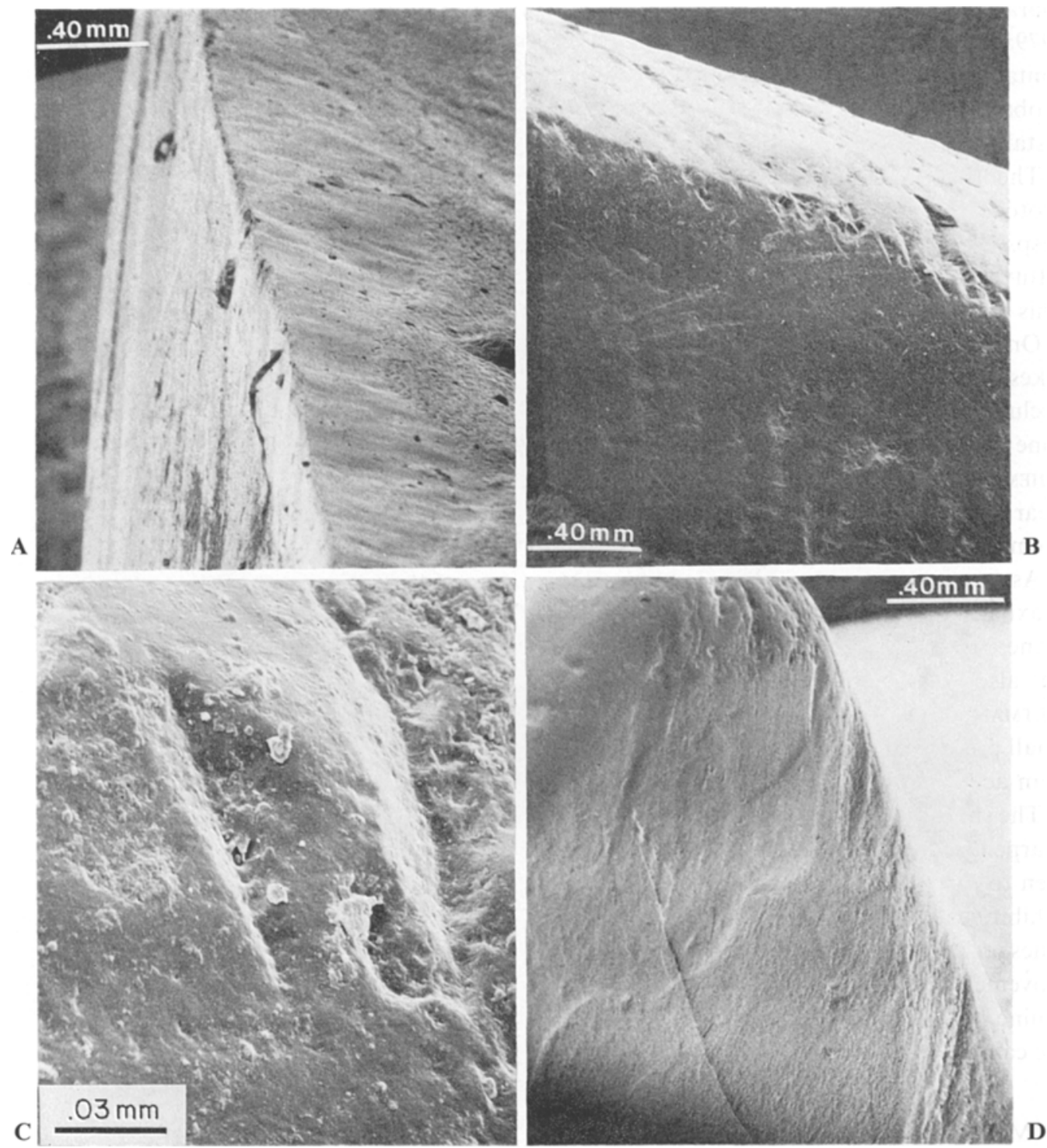

Fig. 8. Single SEM micrographs of dental microwear found on the canine/premolar complex of Papio hamadryas (CMNH No. 1214, male). A. The maxillary left canine illustrated in this micrograph exhibits a sharp shearing edge. Extending from this edge are fine wear striae. B. A wear facet located on the buccal surface of a left $P_{3}$ is illustrated at low magnification. Note that wear striae extend downward from the shearing edge (upper half of micrograph). The lower portion of the shearing edge is polished. C. At high magnification of the wear facet illustrated in Figure 8B, an individual wear striation, wedge-like in form, is shown. The upper half of this striation is broader than the lower portion, characteristics of the direction of wear. This wear striation morphology indicates that this striation as well as others along the shearing edge correspond to Phase I of mastication when the mandible is drawn upward, forward and slightly medially into centric occlusion. $\mathbf{D}$. The distal wear facet of the mandibular left canine illustrated in this micrograph exhibits polish and wear striae. Both features may correspond to sliding contact made with the mesial portion of the upper canine during jaw closure. 
characteristics that correspond to the direction of Phase I movements of the jaw (see RYAN, $1979 \mathrm{a}, \mathrm{b}$ for further details). It appears that the honing buccal surface of the $\mathrm{P}_{3}$ comes into contact with the shearing edge of the maxillary canine during mastication. Phase I, then, probably serves a dual purpose in canine/premolar function: (1) the sharpening of the canine distal edge and (2) the cutting of food.

The lower premolars of the pongids studied also exhibit extensive pitting on the tip of the protoconid. The blunting of the $\mathrm{P}_{3}$ cusp tip as well as the cavitation and flattening of canine cusps, especially seen in older individuals, are probably related to initial "puncture-crushing" (HIIEMAE \& CROMPTON, 1971) jaw movements during which a large bolus of food is reduced. This puncture-crushing activity also is referred to as "chopping" in humans (AHLGREN, 1966).

Once food is initially punctured and crushed and then sliced (during Phase 1), grinding takes place. During this activity, the mandible moves downward and medially out of centric occlusion. Grinding of food takes place in molar basins as food is mashed between the protocone and talonid basin. This grinding activity has been called Phase II of mastication (KAY \& Hiremae, 1974a). In mammals, Phase II wear striae often can be observed on molars. Microwear corresponding to Phase II movements of the jaw are not observed on the pongid anterior premolars discussed here indicating that these teeth do not function primarily to grind food.

As in pongids, canine tooth sexual dimorphism is pronounced in the Cercopithecoidea. Maxillary canines are especially sharp and large in males, extending well below the occlusal plane. Sexual dimorphism in canine size not only reflects male/female body size differences but also intra-specific competition for females (DUNBAR, 1976). Although ALtmanN and Altmann (1970) point out that adult males may defend the troop from attacks made by small predators, hamadryas baboons as well as other primates usually rely on "flight" rather than actual combat (DUNBAR, 1976).

The sharp shearing edge of a male canine is illustrated in Figure $8 \mathrm{~B}$. This edge is continually sharpened by the honing buccal surface of the $P_{3}$. At high magnification, V-shaped wedges are seen to extend from the shearing edge of the $P_{3}$ toward the base of the crown. These wedges exhibit morphological characteristics of direction indicating that sharpening of maxillary canines and slicing of food take place during an upward, forward and mesial mandibular movement (Phase I; see RYAN, 1979c for an analysis of wear striation morphology on the canine/premolar complex of $P$. cynocephalus). For a macroscopic analysis of wear facets on the canine/premolar complex of Cercopithecinae and Colobinae consult ZiNGESER (1969).

\section{SUMMARY}

It has been shown that distinct sets of microwear types are found in Pan troglodytes, Gorilla gorilla gorilla and Papio hamadryas. These sets of dental microwear types primarily reflect differences in dietary composition and the ways in which food is initially chewed and manipulated. Chimpanzees, who are primarily frugivorous, exhibit a relatively high density of small pits and wear striae that are oriented more mesiodistally. These microwear types are probably associated with the husking of hard fruit exocarps and the lateral pull of leaves across teeth, respectively. As compared to chimpanzees, gorillas, who are herbivorous, exhibit large areas of polish, fine wear striae oriented more labiolingually and small pits. This microwear set is probably related to the stripping of leaves and pith and in part to the occasional husking of fruits. Polish and wear striae seem to be interrelated since the repeated action of small abra- 
sive particles drawn across tooth surfaces can lead to either microwear feature. However, polish may also occur when food containing small amounts of abrasive particles is chewed. A very different set of microwear types is found on the incisors of Papio hamadryas, a savanna dwelling baboon. Here, extensive labial enamel edge damage, large pits and microflaking probably correspond to the chewing of gravel-laden seeds, rhizomes and roots, food obtained from the savanna floor.

Microwear found on the canine/premolar complex of the nonhuman primates studied is basically similar, although differences in morphology are manifest. The honing buccal surface of the lower anterior premolar possesses a large polished and striated cutting edge. Wear striation morphology on this shearing surface indicates that the sharpening of maxillary canines as well as the slicing of food are accomplished during Phase I of mastication. The lower premolars also may exhibit extensive pitting of the cusp tip. The blunting of the $\mathrm{P}_{3}$ as well as the flattening of canines, two aspects of wear that are pronounced in older individuals, may correspond to the puncture-crushing of food during initial chewing.

It is apparent from the results presented here that it is not possible at this time to link specific types of microwear to particular food items. The abrasive material found in plant foods or introduced into the diet have not been subjected to detailed analysis. We also do not know how much vertical force is required to pit, scratch or flake enamel and dentine nor do we know whether or not all plants score occlusal surfaces. Specific dietary information may be gained through various experimental analyses including the use of wear producing devices designed to produce microwear features on unworn teeth (RYAN, 1979b) and/or by feeding experimental animal foods containing various abrasive particles isolated from different plants. When these experimental approaches are systematically utilized along with comparative studies of dental microwear in other primates, it may be possible to provide additional information concerning the direct relationship between features of microscopic tooth wear and dietary composition.

Acknowledgements. I would like to thank Dr. D. C. Johanson, Cleveland Museum of Natural History, for access to dental materials on which this study is based. This research was supported by the National Science Foundation and the L.S.B. Leakey Foundation.

\section{Appendix}

COVERT and KAY (1981) have recently suggested that wear striae on molars of Didelphis marsupialis do not exhibit characteristics of wear that correspond to Phase I movements of the jaw. These authors argue, for example, that individual wear striations are "deepest and broadest in the middle, with shallow and narrow tails at both ends" (COVERT \& KAY, 1981). However, a careful examination of the micrographs presented by these authors (Figs. 3A-C) reveals that each striation shown is both pitted and surrounded by large pits. It has been demonstrated by RYAN (1980) that it is difficult to interpret wear striation geometry in striated molar wear facets because these teeth primarily serve to crush and grind food. Wear striae, then, are often pitted and/or obliterated by puncture-crushing or grinding abrasive material. Distinct and clear individual wear striations which exhibit direction are often seen on teeth that primarily function to shear and slice food. The wear striations observed on the honing buccal surface of mandibular third premolars, as illustrated in Figure $8 \mathrm{C}$ of this study, show direction, a finding which is most consistent with detailed experimental work (RYAN, 1979a, b).

\section{REFERENCES}

Ahlgren, J., 1966. Mechanisms of mastication. Acta Odontol. Scand. Suppl., 44: 1-109. 
Altmann, S. A. \& J. Altmann, 1970. Baboon Ecology. S. Karger, New York.

Boucher, C. O., 1963. Current Clinical Dental Terminology. C. V. Mosby Co., St. Louis.

Butler, P. M. \& J. R. E. Mills, 1959. A contribution to the odontology of Oreopithecus. Bull. Brit. Mus. Nat. Hist. (Geology), 4: 3-26.

COVERT, H. H. \& R. E. KAY, 1981. Dental microwear and diet: Implications for Determining the feeding behaviors of extinct primates, with a comment on the dietary pattern of Sivapithecus. Amer. J. Phys. Anthropol., 55: 331-336.

Crompton, A. W. \& K. M. Hiremae, 1970. Molar occlusion and mandibular movements during occlusion in the American opossum, Didelphis marsupialis. Zool. J. Linn. Soc., 49:21-47.

Crook', J. H. \& P. ALdRich-BLAKE, 1968. Ecological and behavioural contrasts between sympatric ground dwelling primates in Ethiopia. Folia Primatol., 8: 192-227.

DeVore, I. \& S. L. WASHBURN, 1963. Baboon ecology and human evolution. In: African Ecology and Human Evolution, F. C. Howell \& F. Bourlière (eds.), Viking Fund, Chicago, pp. 335-367.

Dunbar, R. I. M., 1976. Australopithecine diet based on a baboon analogy. J. Human Evol., 5: 161167.

Goodall, J., 1963. Feeding behaviour of wild chimpanzees. In: Primates, J. NAPIER \& N. A. BarnIсот (eds.), Academic Press, New York, pp. 39-47.

- 1965. Chimpanzees of the Gombe Stream Reserve. In: Primate Behavior, I. DEVore (ed.), Holt, Rinehart \& Winston, New York, pp. 425-473.

- 1968. The behaviour of free-living chimpanzees in the Gombe Stream Reserve. Anim. Behav. Monog., 1: 161-311.

Hitemae, K. M. \& A. W. Crompton, 1971. A cinefluorographic study of feeding in the American opossum, Didelphis marsupialis. In: Dental Morphology and Evolution, A. A. DAHLBERG (ed.), Univ. of Chicago Press, Chicago, pp. 299-334.

Jones, C. \& J. SABATER Pí, 1971. Comparative Ecology of Gorilla gorilla (Savage and Wyman) and Pan troglodytes (Blumenbach) in Rio Muni, West Africa. Bibliotheca Primatologica, No. 13, S. Karger, London.

KAY, R. F., 1973. Mastication, molar tooth structure and diet in primates. Ph.D. dissertation, Yale Univ., New Haven, Connecticut.

1975. The functional adaptations of primate molar teeth. Amer. J. Phys. Anthropol., 43: 195-215.

1977. The evolution of molar occlusion in the Cercopithecidae and early Catarrhines. Amer. J. Phys. Anthropol., 46: 327-352.

\& K. M. HiIEMAE, 1974a. Jaw movements and tooth use in recent and fossil primates. Amer. J. Phys. Anthropol., 40: 227-256.

\& ___ 1974b. Mastication in Galago crassicaudatus, a cinefluorographic and occlusal study. In: Prosimian Biology, R. D. Martin, G. A. Doyle \& A. C. Walker (eds.), Duckworth, London, pp. 501-530.

Kortland, A., 1962. Observing chimpanzees in the wild. Sci. Amer., 206:128-138.

KuMMer, H., 1957. Soziales verhalten einer mantelpavin. Gruppe Schweizzeitsch. Psychol., No. 33. , 1968. Social Organization of Hamadryas Baboons. Univ. of Chicago Press, Chicago.

1971. Primate Societies: Group Techniques of Ecological Adaptation. Aldine, Chicago.

Merfield, F. G. \& H. Miller, 1956. Gorilla Hunter. Farra, Straus \& Cudahy, New York.

MilLs, J. R. E., 1955. Ideal dental occlusion in the primates. Dent. Practner., 6: 47-61.

Nishida, T. \& S. Uehara, 1980. Chimpanzees, tools and termites: Another example from Tanzania. Cur. Anthropol., 21: 671-672.

ReYnolds, V., 1965. Budongo, an African Forest and Its Chimpanzees. Natural History Press, New York.

1967. The Apes: The Gorilla, Chimpanzee, Orangutan and Gibbon. E. P. Dutton, New York. \& F. Reynolds, 1965. Chimpanzees of the Budongo Forest. In: Primate Behavior, I. DeVore (ed.), Holt, Rinehart \& Winston, New York, pp. 368-424.

RYAN, A. S., 1979a. A preliminary scanning electron microscope examination of wear striation direction on primate teeth. J. Dent. Res., 58: 525-530.

$-1979 \mathrm{~b}$. Wear striation direction on primate teeth: A scanning electron microscope examination. Amer. J. Phys. Anthropol., 50: 155-168. 
1979c. Tooth sharpening in primates. Cur. Anthropol., 20: 121-122.

1980. Anterior dental microwear in hominoid evolution: Comparisons with human and nonhuman primates. Ph.D. dissertation, Univ. of Michigan, Ann Arbor, Michigan.

SABATER Pí, J., 1966a. Rapport préliminaire sur l'alimentation dans la nature gorilles du Rio Muni (Ouest Africain). Mammalia, 30: 235-240.

-, $1966 \mathrm{~b}$. Gorilla attacks against humans in Rio Muni, West Africa. J. Mammal., 47: 123124.

Schaller, G. B., 1976. The Mountain Gorilla: Ecology and Behavior. The Univ. of Chicago Press, Chicago.

St. Hoyme, L. E. \& R. T. Koritzer, 1971. Significance of canine wear in pongid evolution. Amer. J. Phys. Anthropol., 35: 145-148.

Suzuki, A., 1969. An ecological study of chimpanzees in a savanna woodland. Primates, 10: 103-148.

Swindler, D. R., 1976. Dentition of Living Primates. Academic Press, London.

TeleKI, G., 1974. Chimpanzee subsistence technology: Materials and skills. J. Human Evol., 3: 575594.

--, 1975. Primate subsistence patterns: Collector-predators and gatherer-hunters. J. Human Evol, $4:$ : 125-184.

WALKER, A., 1979. SEM analysis of microwear and its correlation with dietary patterns. Amer. J. Phys. Anthropol., 50: 489. (Abstract)

WALKER, P. L., 1976. Wear striations on the incisors of Cercopithecid monkeys as an index of diet and habitat preference. Amer. J. Phys. Anthropol., 45: 299-307.

Washburn, S. L. \& R. L. Ciochon, 1974. Canine teeth: Notes on controversies in the study of human evolution. Amer. Anthropol., 76: 765-784.

Weier, T. E., C. R. Stocking \& M. G. Barbour, 1970. Botany: An Introduction to Plant Biology. John Wiley \& Sons, Inc., New York.

Wrangham, R. W., 1975. The behavioural ecology of chimpanzees in Gombe National Park, Tanzania. Ph.D. dissertation, Univ. of Cambridge, Cambridge.

Zingeser, M. R., 1969. Cercopithecoid canine tooth honing mechanisms. Amer. J. Phys. Anthropol., $31: 205-214$.

ZuCKerman, S., 1932. Social Life of Monkeys and Apes. Harcourt \& Brace, New York.

—Received December 23, 1980; Accepted May 9, 1981

Author's Name and Address: Alan S. RYan. The University of Michigan, Center for Human Growth and Development, 1111 E Catherine, Ann Arbor, Michigan 48109, U.S.A. 